\title{
The Quest for Traditions, or a Case of Philosophy of Education
}

\author{
Karsten Kenklies, University of Strathclyde, Glasgow \\ Email:karsten.kenklies@strath.ac.uk
}

A review of: Siljander, P., Kivelä, A. \& Sutinen, A (Eds.) (2012). Theories of Bildung and Growth. Connections and Controversies between Continental Educational Thinking and American Pragmatism. Rotterdam: Sense Publishers.

The review of an anthology always is a special task as there are many different elements and perspectives to be taken into account. On one hand there is the overall structure of the collection which is the result of a specific question or theme that the book aspires to address. In this case, such a theme or question is made clear by the editors in an extensive introduction and answered in the final chapter, which is also written by the editors and which refers to only very few contributions of the collection. The introduction and concluding chapter provide a frame for the other essays which are to contribute in different ways in response to the book's main question or theme.

On the other hand there are of course the different essays which are usually part of academic discussions concerning specific problems which do not fit so neatly with the book's overall question, one that is only occasionally reflected in the micro-structure of these essays. A review that aims to take those different dimensions into account is a very difficult thing: Whereas it seems to be quite straightforward to reflect the overall structure of the volume, it would be hard to argue that the reviewer is equally an expert for all the specific academic discussions to which the single essays contribute in their own special ways. This is true all the more as it is one of the basic assumptions of this volume that there are two very distinct traditions of pedagogical thinking which shall be introduced and whose relation has yet to be clarified. If this assumption is right, it might be very difficult to find someone who is an expert for both traditions in a way that allows her or him to evaluate all essays with equal facility. Keeping that in mind, this review will make only brief remarks about the single essays and focus more on the structure of the whole volume.

Already the title of the book reveals its nature: It is not only oriented towards the presentation of theory, but is also linked to philosophy: Even if one does not know much about what is referred to in the book's title as continental educational thinking, the title's reference to American Pragmatism is revealing. It should prepare the reader for the table of contents, where the chapter titles show just how strongly philosophical the theories in the book are. This could well be the first moment of revelation: Continental educational thinking as it is presented here is closely tied to the tradition of continental philosophy; names like Rousseau, Kant, Fichte and Humboldt are as much classics of philosophy as of educational theory. And it might be useful to remember that even the famous educational theorist Herbart did not hold a chair solely in pedagogy, but rather in philosophy and pedagogy - being the successor of Immanuel Kant in Königsberg. Educational thinking in this tradition is part of the all-encompassing endeavor to give an interpretation of the conditio humana, known in the German speaking world as Anthropologie.

American Pragmatism is not so much different in its aspirations as it evolved out of and in discussion with this continental tradition of philosophical and educational thinking. But it was not only the Pragmatists who had strong personal and theoretical connections to the old world - the continental tradition was familiar to North American educational theorists 


\section{Kenklies}

and practitioners in the $19^{\text {th }}$ century, and at least until time of the first World War: Fröbel's Kindergarten was perhaps one of the first educational imports into America, with the first private kindergarten opened in 1856 by Margarete Schurz in Wisconsin, followed by the first public kindergarten in 1873 in St. Louis. Also, 1861 saw the opening of the Pestalozziinspired Oswego Normal and Training School in New York State, and William T. Harris, schools inspector of St. Louis and later US Commissioner of Education, introduced an emphatically Hegelian perspective on education both locally and nationally. Finally, between 1885 and 1912, over 200 American pedagogues travelled to Jena to study with the followers of Herbart who were active there, bringing the educational philosophy of Herbartianism back to the United States.

However, this strong and steady stream of influence, flowing from Europe to North America, was reduced to little more than a trickle by the early $20^{\text {th }}$ century. Indeed, if there is any Transatlantic influence to speak of today, it clearly flows the other way, with American trends and buzzwords appearing ever more frequently in German-language discourses. Looking historically, educational research can be said to have been reinvented similarly but independently in both worlds, becoming what we nowadays call empirical research, and with philosophically informed thinking about education significantly marginalized. Research into education now usually means collecting (often short-lived) insights into educational reality (consisting of brute facts and raw data). This is despite the fact that it is somewhat ambitious to refer to this as a "reality", since the foundations for giving a 'thick description' (to borrow a term of Gilbert Ryle and Clifford Geertz) of what is represented by 'facts' and 'data' are not already included in the collection of those data. Simply put, brute data on their own just don't make sense.

Still — something only makes sense precisely if sense is made from it. And this is what we are forcefully reminded of when reading a book like the one in question: We still need an interpretation of what it means to be human and what this has to do with anything we might call pedagogy. We need this in order to understand what's going on in the (educational) world. Such needs cannot be easily satisfied - as the book also shows. But in presenting different views and perspectives upon the world of pedagogy, the book invites us to firstly appreciate and, perhaps, remember the necessity of this kind of thinking. Secondarily, it invites us to muse about what we generally have to think about in attempting to address these needs and the questions that lie behind them.

The overall assumption on which this volume is based and structured is introduced with notable understatement on the first page of the introduction: "The tradition of modern European educational and educational-philosophical thinking, with its variants, usually appears different than the tradition of Anglo-American educational-philosophical research." (p.1) This difference is connected to (or maybe even caused by) the different key texts upon which those traditions are built: Whereas the continental tradition rests upon writers like Comenius, Rousseau, Kant, Hegel, Fichte, Herbart, Humboldt etc., American educational thought often looks to the pragmatists, Dewey, James, Mead, Mann and others. However, recent philosophical research has been pointing towards connections between these different ways of thinking - and so it seems natural to expand these connections and investigations.

This is the aim of the book: "In this work, a dialogue is sought between the educational thinking of the classics of American pragmatism and the so-called Bildungtheoretical tradition of thought, which took shape mainly in the German language area" (p.2). This approach is narrowed down by identifying two central notions which apparently lie at the core of those traditions: Bildung (continental) and growth (Anglo-American). Expecting that not all readers may be familiar with these concepts, the editors offer a brief introduction into each of and identify historical connections between several exponents of these concepts. Such explanations mark the transition to the essays which are grouped together into two main 
sections: Whereas the first investigates the continental tradition of Bildung and its modern guises (e.g. Comenius, Rousseau, Fichte, Kant, Herbart, Humboldt, Adorno) the second chapter examines proponents of the American (pragmatist) tradition (e.g. Emerson, Mann, James, Dewey, Mead). In general, the essays presented in the book can be characterized as historical and/or systematic, where the different authors vary in their specific emphasis on either presenting a theory in its systematic context or in its historical connections. However, the overall theme of the book is hardly addressed in its individual contributions, at least as is stated by the editors:

Although the ideas of Bildung and growth form - when very broadly interpreted - a theme central to those reviews, most of the articles are not limited to Bildung and growth, but rather open an examination of wider education-related questions and contexts. Each article is an independent work and can be read as such. (pp.11-12)

Besides the one essay of Hein Retter, it is only in the closing essay that the editors take on the titular question of the book and elaborate on connections and controversies between what has been introduced as two different traditions.

As has been stated before, it would not be reasonable to review the individual essays as such for that would demand specific types of expertise that are not possessed by this reviewer. However, given the structure of the volume, the articles should cope with a twofold task: On one hand they should contribute to the academic discussion within their specific field of investigation - on the other, they should establish an intellectual horizon within which the specific question of the volume can be reflected upon by the reader.

There is no doubt that the single essays are inspiring and enlightening contributions to the specific debates within their field. They manage to convey the conceptual and historical atmosphere that surrounds the two educational approaches. Whichever tradition the reader is more familiar with, she will find that the articles deepen her own understanding of what is already known on one hand and offer an accessible path into the realms of the lesser known tradition on the other. In addition, the reader will be sensitized to the fact that the picture of those traditions is not at all self-evident, but made up of different interpretations. For example it becomes obvious that Kant's theory of Bildung has a quite different shape depending on which works one focuses upon: Whereas Kivelä relies solely on Kant's lecture on pedagogy (which does not belong to the critical philosophy of Kant and is handed down only as unauthorized listener's notes of a public lecture), Siljander draws the connection between Herbart and Kant based upon an analysis of Kant's critical philosophy and its pedagogical implications. The resulting picture is very different and illustrates how much interpretation goes into presenting positions as "positions," let alone traditions as "traditions."

It therefore does not come as a surprise that the editors in their final chapter also address the matter of connections and controversies between two traditions by refuting the question: The essays have shown that there are more controversies between the (interpretations of the) specific positions within the so-called traditions than between the traditions itself; what has been introduced as a "tradition" and therefore in a sense as a conceptually closed entity turns out to be a conglomerate of very different approaches which might present some historical coherence, but not a conceptual unity. This is the picture that may well dawn on the reader as she compares the different articles to each other in an attempt to answer the overall question of the volume. This impression is deepened by recognizing that although the editors do present broader concepts of Bildung and growth in their introduction, the essays themselves are very much independent from those assumptions and tend to introduce their own ideas of these concepts when necessary. As a result, the overall question regarding the connections and controversies between traditions seems itself difficult 


\section{Kenklies}

to sustain. Indeed, as the editors suggest in their final paper, it seems to be much more beneficial to ask about connections and controversies between specific theories and ideas within each tradition, than try to bring whole traditions into broader interrelationship. Consequentially the editors then present their very own interesting and inspiring concept of education, taking into account the theoretical discussions about Bildung and growth that have been introduced in the essays of the book.

However, the result is ultimately ambivalent: As much as one might want to put the book's central question itself into question, the question remains why it has been posed as such in the first place.

It cannot be denied that this approach has offered a brilliant scheme for a collection of inspiring essays, each of which make a great contribution within academic discussion to which they are particular. However, at least three further sets of questions arise for the reader: Which traditions are sufficiently self-contained on a conceptual level to be presented as a whole and to be compared to each other? And what does it mean to homogenize different concepts to create the image of a tradition in order to then ask after connections and controversies between similarly homogenized traditions? If this remains unaffirmed on the level of individual authors, why dare to talk about whole traditions? Why and to what end is it useful?

The attempt to answer this question brings us to the second question: Even if the essays presented here show that it is very difficult to talk about loose groupings of historical contributions as traditions, the reviewer shares the impression that there is a fundamental difference between the educational approaches of the Anglophone and continental world (perhaps reminiscent of the traditional differentiation between continental and analytic philosophy). However, once this difference is granted, it should be asked whether it is rooted in the difference between continental philosophy of education and Pragmatism, whose connections and filiations to European philosophy are widely known even amongst educational theorists: Dewey is never absent in any historic or systematic portrayal of the Progressive Education or Reformpädagogik, Mead has been made famous as an important contributor for the modern German theory of recognition as proposed by Axel Honneth. Indeed, the connections are clearly illustrated in Hein Retter's contribution to the present volume.

So perhaps we have to look elsewhere to find the basis of difference. Which brings us to the last of the three questions: Is it not already anachronistic to pose the question of the relationship between the two traditions, however they may be conceived? In the light of the success of empirical research on international level, philosophical approaches towards education have long been embattled, a situation which has led to the almost complete eradication of philosophy of education as a sub-discipline in both worlds. With regard to this development, the evaluation of a book like the one discussed here has to take a completely new path: Whatever reservations we might have concerning the book, should we not be very happy to have it? Are we not lucky that a perhaps slightly misleading question guiding it has resulted in a volume that generally shows how beneficial and necessary this type of reflection can be? Have not the editors, in planning such a book, offered the opportunity to keep alive what is in danger of dying?

Keeping that in mind, all the somewhat picayune reservations towards the book enumerated above lose substantiality and the books shines as defender of an ultimately unified tradition of philosophical and historic-systematic reflections about education. Any comparatively minor differences between these traditions are obviously less important than the fundamental differences that distinguish it from the international empirical research that has invaded and conquered Departments of Education all over the world. 